\title{
Towards a Conceptual Model of Design Team Learning in Mechanical Engineering Education
}

\author{
Minha R. Ha \\ Department of Mechanical Engineering \\ Lassonde School of Engineering, York University \\ Toronto, Canada \\ minhareo@yorku.ca
}

\author{
Aleksander Czekanski \\ Department of Mechanical Engineering \\ Lassonde, School of Engineering, York University \\ Toronto, Canada \\ alex.czekanski@lassonde.yorku.ca
}

\begin{abstract}
Design education is the backbone of the undergraduate Mechanical Engineering (ME) curriculum at Lassonde School of Engineering (LSE). ME students take project-based design courses every year of their program. Students in the design courses were surveyed and interviewed, in order to examine the key learning outcomes and their development over the undergraduate years. Early-stage coding and analysis on the interview data have resulted in (1) the identification of possible threshold concepts in each year of project-based design learning, (2) the variation and changes in the meaning of design across cohorts, and (3) the three-level factors to design team success. Recommendations are proposed for the instructional training and course structure to enhance their support for design team project experience and outcomes.
\end{abstract}

Keywords- design education; project teams; mental models; threshold concepts

\section{INTRODUCTION}

What is engineering design (ED)? Design engineering is embedded in the contexts of techno-scientific, socio-cultural, and econo-organizational realities; it also serves as a central convergence point for transdisciplinary knowledge integration to occur [1], [2]. As such, many scholars have made efforts to define the nature of engineering design [3]-[5], and the abilities of a design engineer [6]-[10].

How educators understand design abilities shapes curricular decisions that structure student learning. In the context of our design curriculum, an early and repeated engagement of engineering students with project-based learning in engineering design serves multiple purposes. First, the design projects closely resemble the practice environment, providing an opportunity to more accurately grasp the nature of the complex engineering work [10]. Projects involve change management, knowledge integration, and interpersonal work that require practice and feedback. Students "act out the role of designer" [6], the opportunity for which is not often available in individual, separately topic-based courses.
Second, the design projects empower students to take active ownership and receive recognition for their creative work. Producing tangible outcomes builds confidence, motivates engagement, and is expected to motivate prolonged engagement in the engineering field [11]. At the same time, because of the 'realness' students perceive in the project experience, design projects become an educational environment where students "come to care about the valuable things involved” (Peters 1965, quoted in [11]) - and reveal what things are actually valued in the institutional program. All such aspects are expected to enable reflection and deep changes in the way students understand and relate to their work in engineering design.

However, the preference for project-based learning for engineering design lacks in comparison a robust empirical and theoretical explanation of the actual learning processes that take place. How do students learn engineering design, or develop as design engineers? This is not a straightforward question; and as we have delved into the study of design learning in our curricular setting since 2015, we have undergone changes in our own 'mental models' of ED teaching and learning. Mental models are "our understanding of the causal structures of the system, the boundary we draw around the system, the time horizon we consider relevant, or our goals and values... our framing or articulation of a problem" [12]. Student perspective data from our longitudinal study has pushed us to articulate and have an honest look at our choices, assumptions, and expectations as educators.

This paper focuses on the unexpected findings from student interviews that link design project teams' interpersonal dimensions much more closely to the design performance than previously expected. Originally, teamwork skills were considered complementary but not core to the design team performance. We will demonstrate how students' experiencebased insights can be used to develop a useful framework of design team effectiveness that potentially enhances the teaching content and strategies for design projects. Design is indeed social and ethical in nature [13], [14]. The findings helps start to fill the gap in otherwise strongly cognitivefocused understanding of design education [15], and takes 
further the affective and moral attitudes into practical team competencies.

The paper also summarizes key findings in the potential threshold concepts in design learning. Threshold concepts are learning outcomes that are difficult to achieve, but once achieved, they are irreversible and transformative [16]. This fits well with the view of learning as experiential 'process of change' or 'process of becoming' [17]. The threshold concept theory allows the researcher to focus on difficult, transformative learning outcomes (rather than attempt to document all results of learning). Student perspectives offer much value in this research because they are highly self-aware of the transformative changes, and the struggles they experienced in that transformation.

Therefore, in order to build our understanding of how students learn engineering design, this paper addresses two questions: (1) What key changes do students experience? (2) What enables design project team success for students? The results on design learning trajectory and design team success are expected to contribute useful teaching and learning materials, and also inform course design decisions on the sequence and focus of training.

\section{CONTEXT OF THE STUDY PARTICIPANTS}

The undergraduate Mechanical Engineering (ME) curriculum at Lassonde School of Engineering (LSE) has a strong design focus. Students take a full project-based design courses every year in their winter semester. The general first year design course focuses on problem solving process and techniques (from problem identification to prototyping). Second and third year design courses are for ME students only. The capstone (final year) course is multidisciplinary, involving students from ME, Electrical Engineering and Computer Science (EECS), and Earth Sciences and Space and Engineering (ESSE).

Project-based format is chosen because of the expectation that is mimics real-life practice, and enables 'learning by doing.' Most importantly, spending time to move through one complete cycle of design process is of critical importance, for design abilities are expected to be demonstrated in practice theoretical knowledge of design methodologies must be applied in practice. There is a possible weakness that students are not asked to abstract the design methodology based on their experience, which may or may not contribute to their ability to perform in different methodological frameworks (or innovate their methodologies).

ME students are exposed to multiple design philosophies and approaches in their first year and capstone courses (which are common courses to LSE students, working with peers across departments). In $2^{\text {nd }}$ and $3^{\text {rd }}$ year ME design courses, however, the course deliverables closely follow the conventional design process developed by Pahl and Beitz [7], which is a well-known conventional design methodology in the ME context [18]: conceptual design, embodiment design, prototype report and final report are submitted. Earlier reports are especially important for facilitating frequent feedback, and managing project timelines. Recognizing the importance of teamwork skills, the following modules are integrated into the courses via lectures, assignments and tutorial activities: team contract, peer evaluation, problem-solving style assessment, conflict resolution skills, and personal reflection.

\section{Methodology}

\section{A. Data Collection}

Data were drawn from a larger longitudinal study on the program effectiveness and learning processes in engineering design. In particular, this paper draws data from second (UG2) to fourth (UG4) students in Mechanical Engineering, who participated in the In-Program Survey by and the in-depth interviews that followed. The survey participants were recruited through class announcement and an online link posted on the learning management system; in some courses some class time was allotted to conduct the survey in paper format. Research staff visited classes in a way that no researcher was also a teaching assistant or instructor in the class visited.

In-depth interviews included in this paper were conducted by two female members of the research team (including the first author). Both interviewers represent racialized minorities as well the female presence in an otherwise male-dominant undergraduate program in ME. Interview participants were recruited through the In-Program Survey (by indication of interest), and by posting recruitment message on the learning management system. The total numbers of participants in the In-Program Survey and in-depth interviews are included in Table I.

TABLE I. NUMBER OF RESEARCH PARTICIPANTS

\begin{tabular}{|l|l|c|}
\hline Data Collected in & \multicolumn{1}{|c|}{ In-Program Survey } & In-Depth Interview \\
\hline $\begin{array}{l}\text { Sept 2015 - Aug } \\
2016\end{array}$ & $\begin{array}{l}\text { Only Entrance } \\
\text { Survey conducted }\end{array}$ & UG3: 3 male \\
\hline $\begin{array}{l}\text { Sept } 2016 \text { - Aug } \\
2017\end{array}$ & UG2: 73 & UG2: 2 female, 4 male \\
UG3: 21 & UG3: 2 male \\
Sept 2017 - Aug & UG2: 32 & UG4: 2 male \\
2018 & UG3: 36 & Recruitment ongoing \\
\hline
\end{tabular}

\section{B. Data Analysis}

Written survey responses were reviewed and categorized based on key themes that emerged. The category labels (open codes) were compared to identify possible properties and dimensions that would help relate and group the labels further.

Coding of interview data adapted the Grounded Theory analytic procedures outlined by Strauss and Corbin [19]. Interview transcripts were first coded by paragraphs (open coding), offering a quick summary of each transcript. Relationships between open codes, and hence specific sections of the data, were identified (axial coding). Several versions of potential categories emerged and guided the subsequent data collection. For example, in 2017, a potential model of design learning in team projects was developed. In 2018, a new focus on the factors/features of design team success resulted from added data analysis (Table III). Once the potential categories were chosen, student data were extracted and organized based on the categories. The summaries and category-based enabled volume reduction of the data to be analyzed. 
For some questions, student responses were simply summarized and organized for easy presentation (e.g. Fig. 1). However, interviewees in 2018 were asked to review the preliminary findings from 2017 as well, and invited to confirm/disconfirm, elaborate, and add nuances.

\section{FINDINGS}

\section{A. Key Outcomes in Undergraduate Design Learning}

Third and fourth year students were asked to identify key learning outcomes related to design projects in each year of their program. These are summarized below (Fig. 1):

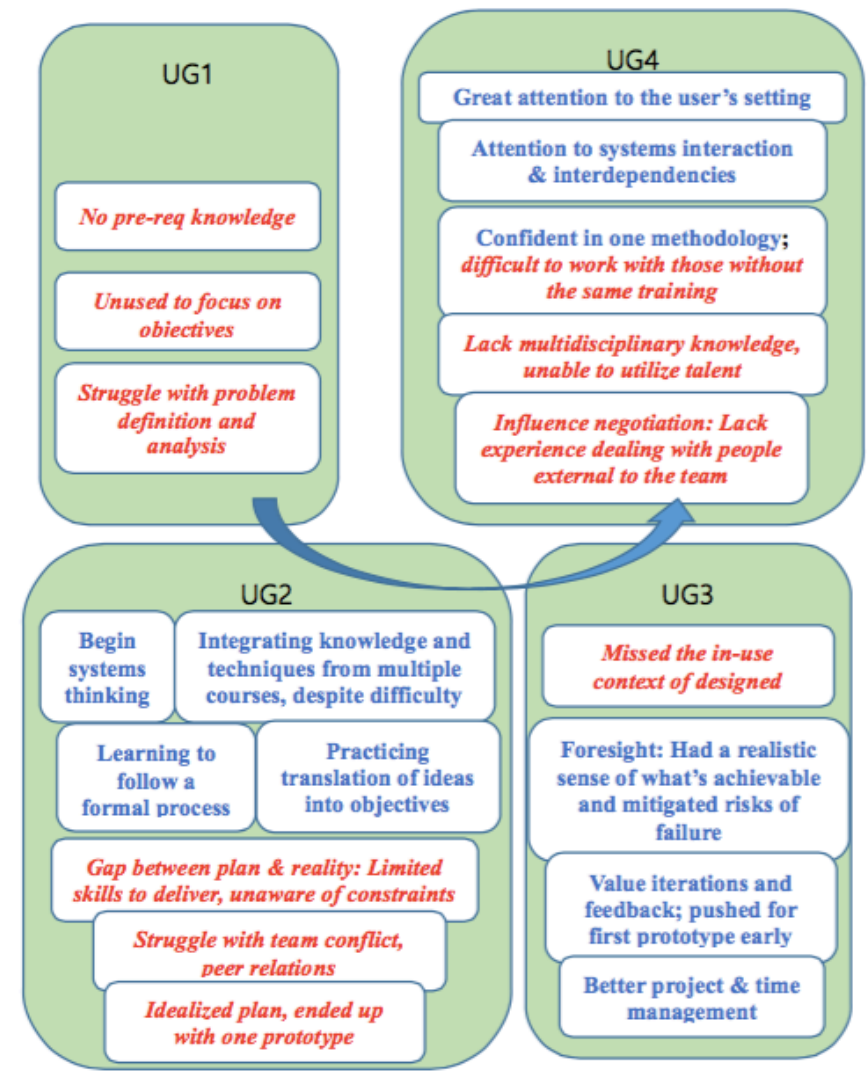

Figure 1. Transformative Outcomes in Design Learning

The italicized text represents self-identified evidence of struggles; bolded text represents self-recognized demonstration of newly achieved abilities. Both attest to the experiences of irreversible change suggesting possible threshold concepts in learning engineering design in our $\mathrm{ME}$ context.

UG1 was a general first year, with design projects that emphasized problem identification and did not require a final product beyond the first prototype. UG2 was the first time ME students had to complete the design cycle, testing prototypes and producing a final outcome. UG3 followed a similar project and course structure. UG4 introduced a new environment for ME students: working in teams with students trained 3 years in different disciplines. Repeat experience in a similar project environment demonstrated more achievements in previously identified challenges; Entering a new project environment identified more new challenges to work on.
Survey responses also confirm the importance of the formal methodology in training thinking habits (Table II). Students were asked to self-identify biggest changes in their approach to design projects. The following key categories emerged:

TABLE II. Key ChANGES IN APPROACHING DESIGN PROJECTS, FROM UG1 TO TIME OF SURVEY

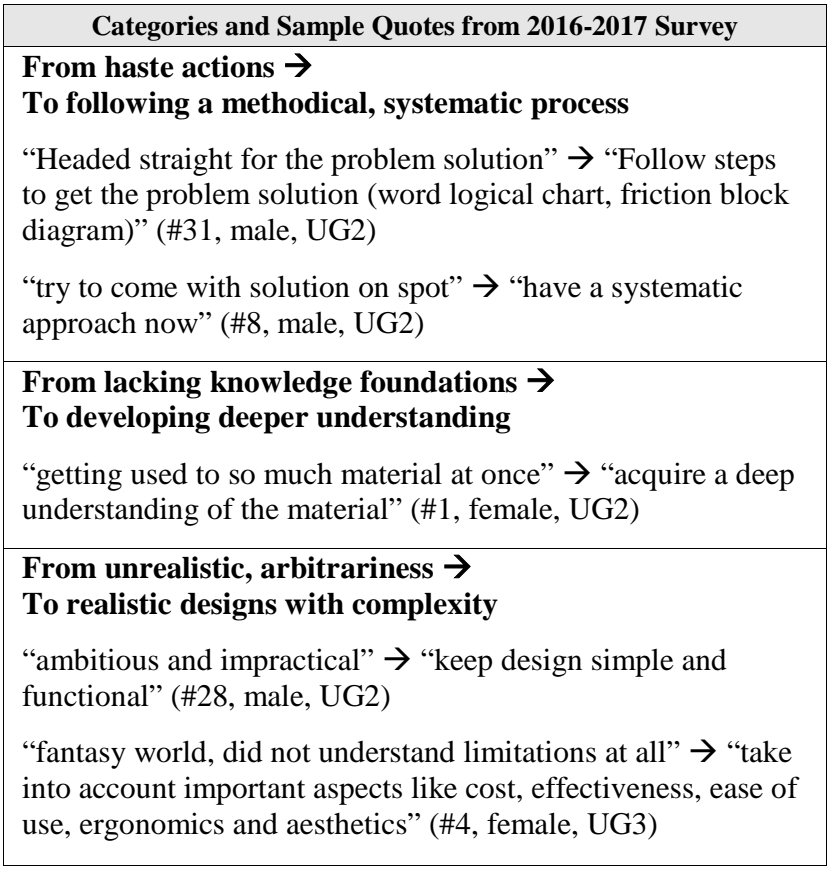

Students' description and explanation of their approaches to engineering design also allude to a 'mental model' of engineering design that guides their action [9]. A crucial part of evolving the mental model is the feedback one receives from real world experiences. An early and repeated exposure of to the experience of engineering design has given students opportunities to become aware of their own limitations and achievements, reflect and practice new habits and skills.

\section{B. The Meaning of Design in Engineering Context}

An important part of the mental model is the understanding of the nature of engineering design, and the students' relationship to the design activity. Design can be recognized as a formal process, an intermediary plan for an artefact (representing characteristics of an artefact), or an output product. One third year student captured the ambiguous use of the term 'design': "Design is both the process in which engineers create and test new ideas (aka the 'design process') but also can refer to a specific style of something ("a certain design was preferred" for example)" (O4, male, UG3, 20162017). Most students chose to describe 'design' in single definitions. Survey responses to the question, "What does 'design' mean, in engineering context?” were first categorized by the type of definition (e.g. design as process, as action, as product, as attribute). The results from 2016-2017 data are presented in Figure 2. 


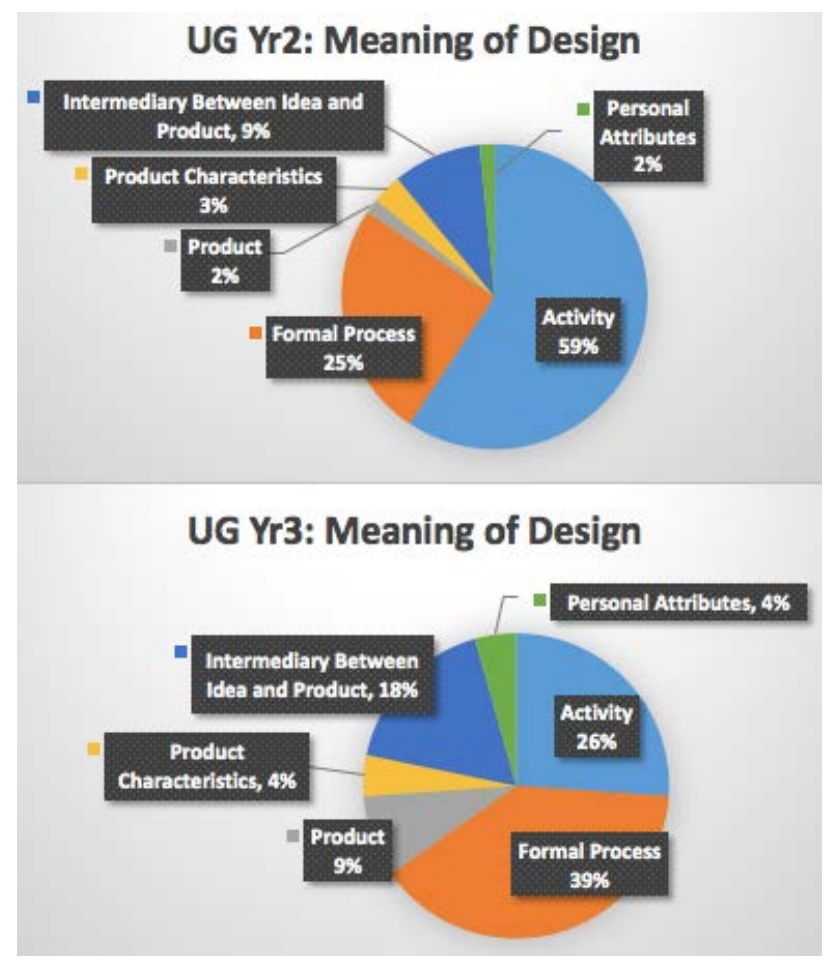

Figure 2. Comparison of UG2 and UG3 Meanings of Engineering Design

It is interesting to note that third year students have a more distributed understanding of what design typifies (a formal process, an output product, and an intermediary between the two). Interview data confirms that students gain a greater recognition of design as a formal process, rather than simply doing something (activity). However, the survey captured a much greater range of responses. For example, the appreciation of the intermediary artefact (that facilitates the translation from an idea to product) was not as clearly selfarticulated by the interviewees (even though the work producing the intermediary artefact was described in detail).

It is important to appreciate the diversity of meanings that persist despite sharing the same curriculum (which has a tendency to create conformity to a limited number of views). Using the term 'design' as a personal attribute, or a characteristic of oneself, suggests a different identity relationship to the work of design than viewing 'design' as a separate product. Translation of an idea into a physical reality, and creativity, remain prevalent goals of design for second and third year students. Referring to some of the interview data, there is a deeply motivating aspect in making something become a physical reality:

[I thought] maybe this isn't for me sometimes. Going into second year then, having the actual project, then something amazing happened. I kept doing it, and I think at this point [I] decided, I'm doing for myself. (S9, female, UG2, 4)

Purpose of engineering design was an embedded part of students' definition of engineering design. The same survey data were categorized based on the implied goals of design in the engineering context. The results from 2016-2017 data are presented in Figure 3.

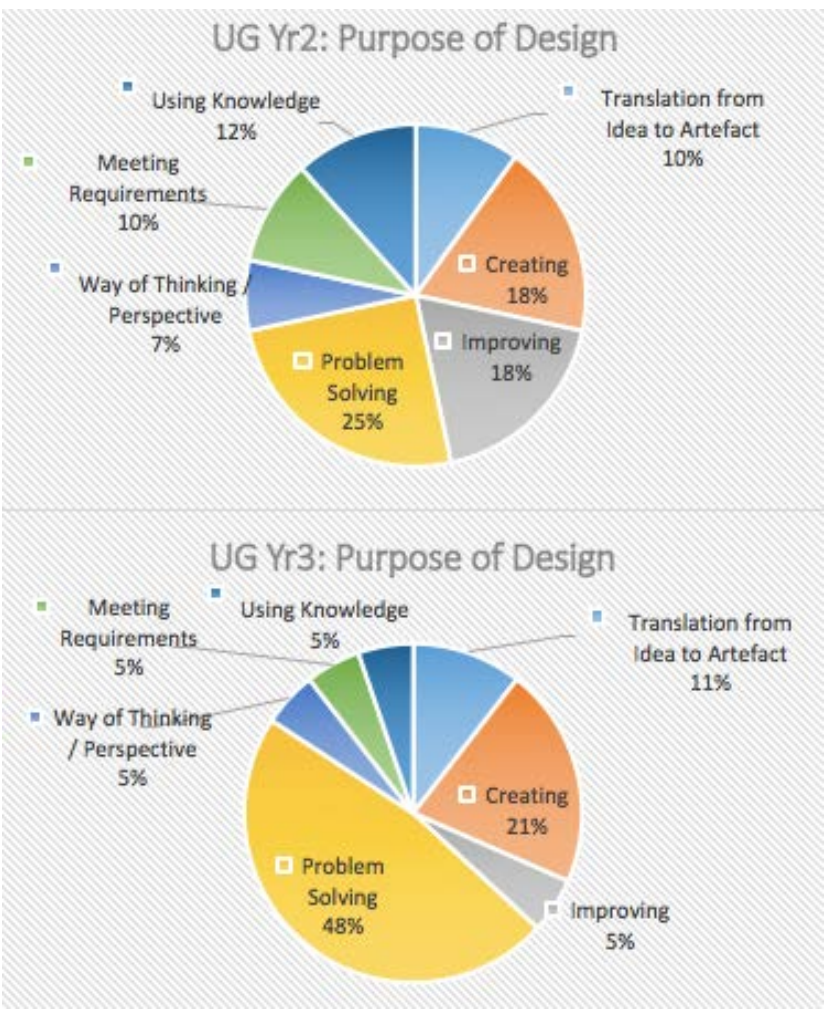

Figure 3. Comparison of UG2 and UG3 Goals of Engineering Design

The close connection between purpose and meaning of design suggests a further investigation into the motivations, aspirations, and values students bring to engineering design. It is also interesting to note that 'social impact' was mentioned in a few responses to the question about the meaning of design, but mentioned much more frequently as reasons to choosing engineering. This aspect is dealt much more effectively in survey and interview data relating to student motivation, and their desired future roles as engineers. These data are not included in this paper.

\section{Three Levels of Design Project Team Enablement}

A significant part of student responses regarding design projects involved experiencing and addressing challenges to team success. There were three distinct types of factors that attributed to team success, with the key concepts organized in the following table. This distinction offers increased clarity and a holistic view of the skills, values, and processes required for an effective team. This also helps explain why, despite separate efforts to establish, e.g. conflict resolution procedures or communication plans, teams might struggle.

Female students, despite fewer in number, offered much more breadth and precision in the use of terminology (Appendix I). Abstracted further by combining both male and female participant voices, the results are summarized in Table III. 
TABLE III. Key FEATURES OF EFFECTIVE DESIGN TEAMS

\begin{tabular}{|c|c|c|c|}
\hline & Level 1 & Level 2 & Level 3 \\
\hline $\begin{array}{l}\text { Descrip- } \\
\text { tion }\end{array}$ & $\begin{array}{l}\text { Individual's } \\
\text { Meaningful } \\
\text { Connection to } \\
\text { the Project }\end{array}$ & $\begin{array}{l}\text { Processes that } \\
\text { Enable Effective } \\
\text { Engagement and } \\
\text { Contribution }\end{array}$ & $\begin{array}{c}\text { Team Culture } \\
\text { and Values } \\
\text { that Foster } \\
\text { Effective } \\
\text { Levels } 1 \text { \& } 2\end{array}$ \\
\hline $\begin{array}{l}\text { Example } \\
\text { Features }\end{array}$ & $\begin{array}{l}\text { Commitment } \\
\text { Priority } \\
\text { Responsibility } \\
\text { Perceived } \\
\text { purpose } \\
\text { Motivation } \\
\text { Learning } \\
\text { Leading } \\
\text { Overall } \\
\text { understanding } \\
\text { of project }\end{array}$ & $\begin{array}{l}\text { Identification of } \\
\text { each member } \\
\text { strengths and } \\
\text { needs } \\
\text { Communication } \\
\text { management } \\
\text { Decision making } \\
\text { Task development } \\
\text { Task allocation } \\
\text { Knowledge } \\
\text { management } \\
\text { Expectation } \\
\text { management } \\
\text { Conflict resolution } \\
\text { Consensus building } \\
\text { Conversations for } \\
\text { understanding } \\
\text { Role clarification }\end{array}$ & $\begin{array}{l}\text { Mutual respect } \\
\text { Fairness in } \\
\text { recognition } \\
\text { Truthfulness } \\
\text { Value for the } \\
\text { person } \\
\text { Goal of shared } \\
\text { success } \\
\text { Inclusivity } \\
\text { Friendship and } \\
\text { belonging }\end{array}$ \\
\hline
\end{tabular}

\section{Level 1: Meaningful Connection to the Design Work}

From students' perspective, a team is successful in its most basic level if all individuals are contributing effectively. Individuals bring their own motivation, behaviour, attitudes, unique needs and strengths. They also carry multiple responsibilities and competing priorities outside the project. For a team working to its "maximum potential" (S9, female, UG2, 13), where people want to do the work, and work hard, an individual must be connected meaningfully to the design project. "[T]hey're doing something more for themselves, and they want it, they're motivated to complete it and to do well in it” (A2, male, UG2, 131). A meaningful connection involves perceived value and importance of the project work, a willingness and desire to achieve a level of standard in that work. A shared understanding of the purpose, scope, and processes of the project is also an important part of that connection (e.g. A1, A2, A3). Openness to learning, and the willingness to collaborate with the team also demonstrate a meaningful connection (e.g. A1).

However, it is also possible to limit team success even when individuals come in with high motivation and ability. It is possible demotivate members, burn out responsible members with unequal work distribution, leave talents under-utilized, or fail to form a cohesive team. "[It is important] to have a friendly environment [so] that it's not something hostile [such] that they don't want to do something” (A2, male, UG2, 131). Each member needs to feel valued in the team, in order to stay connected to the project. The initial motivation and contribution levels can change by the team processes and the team culture. This leads to the Level 2 and Level 3 factors to design team success.

\section{Level 2: Practical Strategies to Enabling Level 1}

Level 2 deals with practical strategies to enable effective contribution and meaningful engagement of team members:
[You must] figure out a way where everyone is involved. Sometimes for team meetings, or brainstorming, you want to get everyone's opinion, you want everyone to be present and to be part of it. (A1, male, UG2, 117)

Such practical strategies to ensure member engagement, integration, and contribution included: identifying individual members' strengths and learning needs (e.g. A1, A3, S7), balancing autonomy and peer learning (S7, A2), structuring meetings for active input (S9), adapting communication strategies for members with different needs (S7), holding constructive conversations when Level 1 is not working (S9), adapting managerial styles (A2), managing expectations and building a common understanding of the team processes (S7, S9, A1), inviting input and feedback (S7, A3, A1), and checking into individual experiences and well-being (S7).

It is important to note that individuals may need different styles of onboarding or integration before they can engage comfortably with the rest of the team:

Two of our members were very quiet. I was really close with one of them and my friend was close with the other. We said, I'm in charge of this one, etc., we said we're going to make sure you are in the loop[...] That allowed us to have a conversation, and helped him express himself.

$$
\text { (S7, female, UG2, 25) }
$$

Disengaged members and team conflicts pose significant challenges to project teams, and students actively reflect on how they might encourage and enhance motivation and performance of individuals. Level 2 processes would include strategies to mitigate challenges and resolve conflicts:

If everyone is upset with that obviously they're going to something about it. And instead of making everyone upset, I could just go up to that guy and try to convince him - you need to start working or this project will not work as smoothly as it

could. There would be problems, there would be conflicts, other people will start saying we're doing too much work and he's not doing any work, why do we have to do work? So, to avoid those conflicts, I would just approach the person ahead of time. (A1, male, UG2, 148)

[S]ometimes it takes people have to realize, you have try and show them, that that's what they want to do, that that's something they should focus on and be motivated to do."

$$
\text { (A2, male, UG2, 150) }
$$

[W] had a member who thought they were smart and said they knew what they were doing ... it got better but it was a lot of work with him... the rest of the team project was making sure everyone had a chance to say. (S7, female, UG2, 12)

Students also commented on the factors that make each team and situation different. Part of being able to lead a team was to recognize the circumstantial or historical variations that require adapted responses to create effective team strategies:

I think language is a big one. Recognizing language is different to everyone. I may be saying one word but you might think it means something else. Your personal background and 
life has effect. If you value other things above this project and others value it, then that's going to be an issue. If you have any personal issue, let us know, don't tell us what, but we have the right to know. (S7, female, UG2, 74)

When we're working with teams, it's good, cause if you have people of different skill sets and different mindsets [...] the head project manager, you want that person to be less like nitty gritty details and more of a by the book, or figuring out the main of how the over arching things that you want to happen. I guess other people would be doing certain jobs and tasks and I guess they could be creative through it. (A2, male, UG2, 119).

It might depend on the project or the situation you're in. Usually there are many different ways to do things. But there are circumstances where there might just be one certain way, and [...] you'd like to be someone like that. That they'd be able to focus and have their blinders on to that certain way.

$$
\text { (A1, male, UG2, 120) }
$$

In general, male students spoke of Level 2 strategies in terms of convincing someone to do what one believes is correct. The diversity people brought to the team were given meaning only in terms of the project tasks. Factors outside the scope of the project activities were not considered. In contrast, S7, one of the two female interviewees, offered articulate insights on how an individual's behaviour can be interpreted, as information to help adapt Level 2 responses. Furthermore, an individual's ability to contribute was understood as an outcome of internal and external systems that shape a person's holistic well-being:

In [one] phase there might be a leader but it doesn't mean someone else can't take charge. Someone who will make sure things are going on time, and make sure everyone is doing ok, and making sure they're mentally and emotionally ok to do it.

I recognized, 'hey you're not behaving the way you usually do,' then they say, 'yeah, there's this thing that's causing me stress.' That's a leader's point of view, to make sure everyone's doing okay. If I am the leader, there are aspects that I don't know anything about so might say, 'hey why don't you take charge of this?' The leader is the role of... who initiates conversation, but they don't need to be in charge.

$$
\text { (S7, female, UG2, 29-30) }
$$

A team leader, without a formal title, was seen as a person who recognizes the factors to individuals' effectiveness and wellbeing, and facilitated Level 2 processes. The leader's responses helped to correct maladaptive behaviours, meet individual needs, provide support, and create engagement. These interactions served as a catalyst to change individual motivation, behaviour, attitudes, strengths.

Students who establish effective Level 2 processes set certain standards and espouse particular values that help the team mature and adapt. At the same time, in spite of good intentions and known strategies, significant challenges have emerged that thwart the efforts at effective Level 2 processes. The contrast between Level 2 enablers and inhibitors led to the identification of Level 3 factors to team success, presented in the next section.
Level 3: Team Culture that Enables Effectiveness of Levels 1 and 2

Level 3 characterizes the team culture by its core values that are expressed in practical ways. Level 3 recognizes that the emotional and relational qualities of team experience have a significant impact on Level 2 and Level 1 effectiveness. For example, even in the case of a conflict, shared values for honest conversation and respect helped turn the conflict into an opportunity for team building: "[E]verybody spoke and said what they wanted to say in a very respectful way, everyone came out feeling more satisfied” (S9, 33). On the other hand, individuals who did not value communication impeded mitigation processes (Level 2) that left Level 1 issues unresolved: "[A] lot of people view communicating as a very fluffy and unnecessary thing, but it reaches a point where I can't have conversation with you because you don't think you need to have it” (S9, 31). Members can passively disengage as well as actively shut down conversations and hinder team effectiveness: “[T]he problem is that a conversation isn't an argument. To me, we had a lot more arguments than conversations, anytime a conversation was initiated it was shut down” (S7, 70).

Level 3 also directly sustained individuals' engagement and contribution levels in the project (Level 1):

[W] e had a lot of different ideas and different thought processes and that helped with problem solving, because we were friends, we didn't have to be fake nice so we could be honest and be productive. Because we were genuine, we got everything done on time, all that was really good.

(S7, female, UG2, 12a)

Trust, friendliness, inclusivity, and respect created a mutually empowering relational culture (Level 3), which enabled effective role integration and task-work facilitation (Level 2).

Students also experienced how disrespect could manifest in different ways to hinder team effectiveness:

So how some people think they're too good for the group this is a big problem, I work with people who have big egos so I don't feel for them, I don't give them credit for things they didn't do, I don't care, they didn't do the work, they don't get the credit, then the people who do the work, I give them the credit and I boost them. Ethics: people who don't follow those will never be successful in engineering. (S1, male, UG3, 122).

I didn't realize how important it was [to address the issue of disrespect or dysfunction]. I thought it just happened naturally... it was a really interesting learning [experience] [...] He took over, at one point you keep fighting for something, and get nothing [...] Sometimes he thought I was challenging him just because I was clarifying. Unnecessary animosity [...] him trying to prove me wrong, constantly competing with one another, the lack of communication, it was really bad [...] It got better but it was a lot of work with him [...] not accepting the random bits of shut-down, saying hey you're acting like a jerk, [making it clear that] criticism for no reason isn't acceptable. (S7, female, UG2, 55, 49, 59b, 12c, 59a). 
Disrespect can be based on unconscious biases that view peers as less than equal. S1 dealt with a male peer who showed off his material wealth, treated project tasks as not important enough for himself but expected of peers like S1. The confusion of socioeconomic status as merit to project credit, with simultaneous exemption from labour, belittled S1 and the importance of the project work itself. On the other hand, S7 dealt with hostility from a male peer who asserted his dominance over the team, and refused to take S7's input seriously, as legitimate. While this kind of disrespectful attitude has been seen between male peers, the subtle sexism was distinct in the personal offense one took as a challenge to the hierarchy (male dominance, has a right to speak without responsibility over behaviour; female submissiveness, has no right to speak up nor disagree with the dominant male).

Both S1 and S7 had very positive team experiences that emulated Level 3 qualities, of collaborative, mutually empowering culture. It only took single individuals - who took their privileged position to impose a hierarchical relationship to make Level 3 very difficult to achieve.

In contrasting high performance team experience and poor team experience, it is also important to note how each member's Level 1 contribution can affect the Level 3 characteristics of the team. Likewise, one person's poor contribution in Level 1 can affect Level 2 processes, Level 3 culture, and another person's Level 1 connection to the team. From S7's example:

[W] were able to say 'I trust that you're going to read the [meeting minutes] even if you couldn't make it', or 'I trust you'll finish your part of the project without me having to nag you.' [...] I would send a notice about the meeting an hour before, and they would all show up to the meeting, they were able to get started themselves if I was late. $(\mathrm{S7}, 28)$.

[W] e worked on a proposal, I said, 'hey I'll do this and this, but I don't know this, so can you do it?' [...] He didn't do it, it ended up not being done. It was really hard to communicate. We started on passive aggressively, sometimes I just didn't want to go to the meeting. (S7, 36).

Each team member can affect other members in important ways, whether negative or positive, whether intended or not. All three levels of team success are mutually reinforcing.

\section{Discussion}

The sequence of the key learning outcomes, in the context of the ME curricular design, reveals interesting possibilities in structuring the learning experience to support the learning outcomes. Sometimes course directors receive feedback on what is not working, but much less on what is working. There are features about the second year design course that created a pivotal experience for many transformative learning outcomes. Many of these were solidified by the similar course experience in the third year. There were first year material that had a clear connection to the upper year learning outcomes, but could be presented and structured to make that connection clearer. Students felt much more challenged in the fourth year with a changed course environment, while they built much confidence through a familiar course environment that was repeated (albeit with greater complexity in the project content) in the third year experience. There may be a trade-off between building confidence (solidifying achievement in potential threshold concepts) and expanding students' perceived horizon of the learning that lies ahead (growth, awareness of the lacking capabilities, broadening the understanding of the field). Engineering design educators need to be conscious of the tradeoffs, diligently collecting evidence to confirm or disconfirm our beliefs about what achieves the intended learning objectives.

Listening to student perspectives also demonstrated a huge value in identifying learning outcomes that we had not anticipated. This is a direct feedback into our own mental models about what constitutes engineering design learning. Without recognizing such valuable learning outcomes, it may leave certain effective learning experiences or course design features to be dropped in the continuous improvement efforts. Sterman emphasized the importance of going beyond just the simplistic use of feedback to 'improve' decisions. He explained how learning must involve a better understanding of the complex systems that constitute an implicit picture of reality, or how the learner frames the problems in the first place. This indeed applies to the educators themselves, to be in continuous inquiry of what design education in engineering is, how it takes place, and what our roles are.

Evidence suggests that it is possible to lose motivated individuals, and that each member may need different procedures to become fully engaged in a team. Then it becomes important that, before a member becomes or continues to be someone “who doesn't want to do anything” (A3, 146), the team makes effort to adapt and establish Level 2 processes and Level 3 culture. “[R]elationship building should've been done since the beginning of the project. I always try to go out for lunch with the group before we work. I try it a lot... I think that's so important” (S7, 73). The importance of Level 1 contributions cannot be understated; however, an individual member's contribution to team success now includes - beyond task delivery - interactional and relational work that facilitates team procedures (Level 2) and establishes a sustainable team culture (Level 3). Because of the mutually reinforcing reflexivity between each of the three levels, the degree of team effectiveness may be a summative result of:

$$
\begin{gathered}
\text { Team Effectiveness }=a L 1+b L 2+c L 3+ \\
d(\text { L1L2 })+e(L 2 L 3)+e(L 1 L 3)+f(L 1 L 2 L 3)
\end{gathered}
$$

where the weight of each level factor may vary between first to fourth year students.

Disrespect is considered a moral injury to the respect and worth of a person [20]. There is an overall inadequate language and problem identification within male-dominant culture for misbehaviour, disrespect, power dynamics, and subtle discrimination based on socioeconomic status and sex - this may extend to other minority experiences, such as ESL, race, personalities, and disability. Engineering design educators, especially as they are involved in developing team leaders, will need to be better equipped to model and raise the level of student proficiency in equity, diversity, and inclusion. 
The existing level of student leadership and excellence should not be ignored. The ethical sensitivities, creativity, relational competencies and proactive action students bring to team life are indeed impressive. Students offered profound insights on which meaningful educational problems exist, how they are engaging in them, and what resources they would like from the institution. Students are partners and co-creators of our educational program success, as this research has taught us.

\section{ACKNOWLEDGMENT}

For the larger study that embeds this paper, we gratefully acknowledge the financial support by Quanser, National Sciences and Engineering Research Council (NSERC), Lassonde School of Engineering and Queen Elizabeth II Graduate Scholarships in Science \& Technology (QEII-GSST) program.

\section{REFERENCES}

[1] W. E. Eder, "Design Engineering and Needs for Methodology,” in International Conference on Engineering Design, ICED’09, 2009, p. 12.

[2] M. Gibbons and H. Nowotny, "The Potential of Transdisciplinarity,” in Transdisciplinarity: Joint Problem Solving among Science, Technology, and Society. Schwerpunktprogramm Umwelt / Programme Prioritaire Environnement / Priority Programme Environment., J. T. Kleinm, R. Häberli, R. W. Scholz, W. Grossenbacher-Mansuy, A. Bill, and M. Welti, Eds. Birkhäuser, Basel, 2001, pp. 67-80.

[3] P. E. Vermaas, P. Kroes, A. Light, and S. A. Moore, Eds., Philosophy and Design: From engineering to architecture. Springer, 2008.

[4] S. H. Christensen, C. Mitcham, B. Li, and Y. An, Eds., Engineering, Development and Philosophy: American, Chinese and European Perspectives, vol. 53, no. 9. New York: Springer, 2012.

[5] I. van de Poel and D. E. Goldberg, Eds., Philosophy and Engineering: An emerging agenda. New York, NY: Springer, 2010.

[6] N. Cross, Designerly Ways of Knowing. Heidelberg, Germany: Springer, 2006.

[7] G. Pahl, W. Beitz, J. Feldhusen, and K.-H. Grote, Engineering design: a systematic approach, 3rd ed. London: Springer, 2007.
[8] C. Spitas, "Analysis of systematic engineering design paradigms in industrial practice: Scaled experiments,” J. Eng. Des., vol. 22, no. 6, pp. 447-465, 2011.

[9] P. Godfrey, R. Deakin Crick, and S. Huang, "Systems Thinking, Systems Design and Learning Power in Engineering Education," Int. J. Eng. Educ., vol. 30, no. 1, pp. 112-127, 2014.

[10] C. L. Dym, A. M. Agogino, E. Ozgur, D. D. Frey, and L. J. Leifer, "Engineering Design Thinking, Teaching, and Learning," J. Eng. Educ., vol. 94, no. 1, pp. 103-120, 2005.

[11] E. Alpay, a. L. Ahearn, R. H. Graham, and a. M. J. Bull, "Student enthusiasm for engineering: charting changes in student aspirations and motivation,” Eur. J. Eng. Educ., vol. 33, no. 5, pp. 573-585, 2008.

[12] J. D. Sterman, "Learning in and about complex systems," Syst. Dyn. Rev., vol. 10, no. 2/3, pp. 291-330, 1994.

[13] H. Plattner, C. Meinel, and L. Leifer, Eds., Design Thinking Research: Building Innovation Eco-Systems. Springer International Publishing, 2014.

[14] I. van de Poel and P.-P. Verbeek, "Ethics and engineering design," Sci. Technol. Hum. Values, vol. 31, no. 3, pp. 223-236, 2006.

[15] C. Noweski, A. Scheer, N. Buttner, J. von Thienen, J. Erdmann, and C. Meinel, "Towards a Paradigm Shift in Education Practice: Developing Twenty-First Century Skills with Design Thinking,” in Design Thinking Research: Measuring Performance in Context, $\mathrm{H}$. Plattner, C. Meinel, and L. Leifer, Eds. New York: Springer, 2012, pp. 71-93.

[16] J. Meyer and R. Land, "Threshold Concepts and Troublesome Knowledge : Practising within the Disciplines," 2003.

[17] C. Beard and J. P. Wilson, "Exploring Experiential Learning," in Experiential Learning: a best practice handbook for educators and trainers, 2006, pp. 15-44.

[18] T. Tomiyama, P. Gu, Y. Jin, D. Lutters, C. Kind, and F. Kimura, "Design methodologies: Industrial and educational applications," CIRP Ann. - Manuf. Technol., vol. 58, no. 2, pp. 543-565, 2009.

[19] J. Corbin and A. Strauss, "Grounded Theory Research: Procedures, canons and evaluative criteria," Z. Soziol., vol. 19, no. 6, pp. 418427, 1990.

[20] A. Honneth, Struggle for Recognition: the moral grammar of social conflicts. Cambridge, MA: MIT Press, 1996.

[21] S. R. Daly, R. S. Adams, and A. M. Bodner, "What does it mean to design? A qualitative investigation of design professionals' experiences,” J. Eng. Educ., vol. 101, no. 2, pp. 187-219, 2012. 


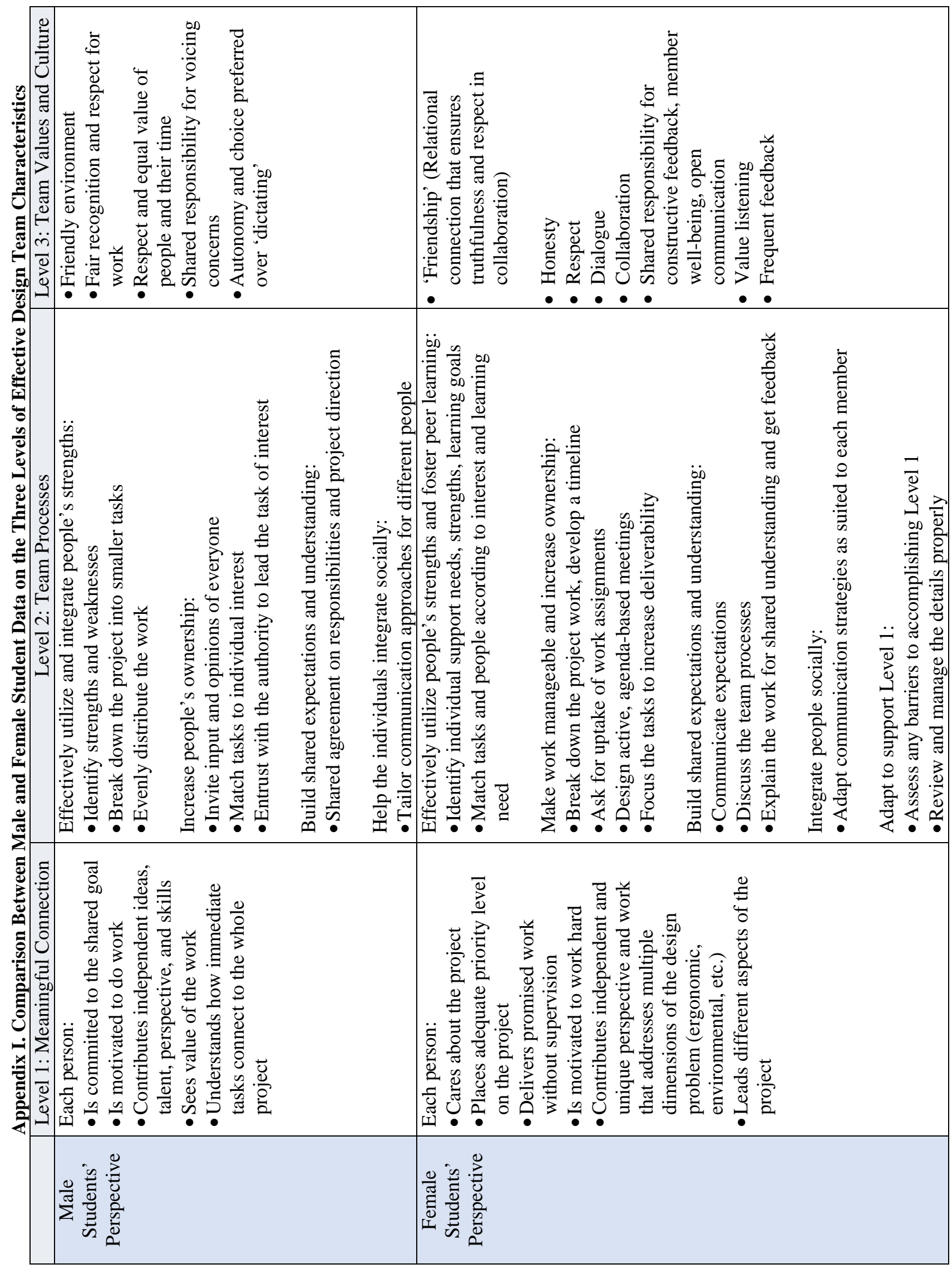

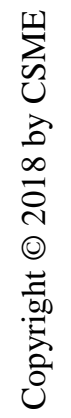

